\title{
Evaluating, Treating and Preventing Deviant Effects of Gambling through Schools and School Curriculums
}

\author{
Ph. D. Candidate Menada Petro \\ Social Sciences Faculty \\ Tirana University, Albania \\ E-mail:menada_petro@yahoo.com
}

Doi:10.5901/mjss.2013.v4n2p381

\begin{abstract}
Studies, in many countries of the world, have proven that gambling starts in childhood and, more precisely between ages of 10 to 19 years old, which agrees with the main period of their education. This paper aims, to shed light on the effects that gambling causes in children and the deviations of their behavior, also its connection with all comprehensive education looking at it as an important mean and instrument for prevention. This study aims to analyze the group effects in pre-adolescents and adolescents, and also the connection that exists between group, age and gambling, observing children and adolescents in some of the places they frequent. Also this paper takes in consideration the elements that influence and effects that gambling causes in children and adolescents. Nowadays we are witnessing more and more adolescents that are getting further from outdoors free activities, instead they are isolated in rooms and places where computer games are played. What interests more adolescents and youngsters today seems to be more concentrated in having or not having money, achieving success in the easiest and fastest way, in the ambition to reach a certain social or political status in order to profit more and fast, in the lack of desire for education and in spending more time and a great amount of money in sport and gambling. This paper aims at the possibility of interfering in the school curricula, especially in the civic education to treat and to know the gambling issues by adolescents, aiming in preventing the deviant effects.
\end{abstract}

Key words: comprehensive education; desire for education; school curricula; prevention; deviant effects

\section{Introduction}

Gambling problems contribute to human poverty and create a monetary cost for the society; however the inside of the problems connected to gambling still remains in the level of conversations and debates.

The expansion of gambling in Albania, in the last years has been a consequence of accepting gambling by the society as a form of recreation, entertainment and as a consequence of justifying the benefits that brings to the country economy through employment. However there is no genuine study of gambling in Albania and the attention towards gambling and its consequences have been sporadic and focused only in casinos and gambling in general, and this was provided by some researchers in the form of personal opinion more than based in the results of a study, even less pretending for a research or opinion of a researcher on gambling among teenagers and children.

The research identifies the risk factors that contribute to problematic behavior in teenagers including narcotic substances abuse, violence, delinquency, pregnancy in adolescence and truancy. Studies on gambling have brought in light that teenagers who are included in gambling are also included in other behavioral problems (Carlson \& Moore, 1998; Vitaro, F., Arseneault, L. \& Tremblay, R. E. 1999; Volberg, 1998; Winters, Stinchfield \& Fulkerson, 1993).

Referring to literature studies, it can be discovered that etiology is the study of causing factors of gambling. Etiological studies are complex and a great number of aspects treated in them have to be taken in consideration. They include the accuracy of diagnostic tags, the connections and the causing relationships between the potential risk factors, unique risk factors age and the group effects.

The definition of psychological and environmental risk factors for problematic and pathological gambling are lead by the following question: Is problematic and pathological gambling connected to socio-demographic factors such as age, gender, family or is it related with the ability and the tendency of gamblers to play? 
The effects of gambling on the individual are the same as the effects caused by alcohol and drugs, but which are the factors that induce the teenagers to play? To answer this question, we should take in consideration some elements of everyday life of teenagers such as (1)age; (2)gender differences; (3)ethnic and socioeconomic status; (4)Family and peer influence; (5)group effect and the relation with other behaviors.

Gambling causes in teenagers and children severe mood disorders, personality and mental health disorders, interruption of family and social relationships, motivation disorders, leaving school or work, inclusion in severe and minor crimes and also suicide.

Youngsters are 4 times more at risk than adults regarding gambling or being problematic gamblers (Wynne, Smith, \& Volberg, 1994; Wynne Resources: Adult Gambling and Problem Gambling in Alberta, 1998). This increase of the number of youngsters may come from the expansion of gambling industry and lotteries in particular and the greater social acceptance and promotion of this industry. In the entrance of different casinos is written "People under 18 are not allowed", but in $95 \%$ of cases this is not applied. Birth certificates, identity cards or other documents are not required to enter in a casino. However this is written only in casinos. There is nothing that can stop a child or a teenager to enter in a place where is played billiards, lottery or bets. Television lotteries are uncontrolled, they encourage youngsters to play by advertising them a pleasure and entertainment in their free time.

The fast development of technology has brought these games inside our houses by making children and teenagers addicted by internet, facebook, and by endless games internet offers. Internet has gambling sites including blackjack, poker, slots and roulettes. Gambling on internet is unexplored and has given a wide spread to the gambling industry through internet. This can be an important investigation of the impacts of this form of gambling in teenagers.

Youngsters with gambling problems are more exposed to have problems with the police; they don't trust their parents, teachers, or their relatives; they feel ignored or refused by their family; they declare not good experiences at school; that their family members have gambled; they bet large amounts of money; they borrow to gamble; steal or sell personal properties or belongings; feel anxious, bored, worried or depressed; smoke; use regularly alcohol or narcotic substances (Randy \& Ken, 2004). The research findings suggest that typical problematic gamblers in youngsters are very disturbed individuals and that excessive gambling is part of a large variety of psychological disturbances, family malfunctioning and other deviant behaviors (Wynne et al., 1996).

Gambling can be part of a group of deviant behaviors that are usually done by males, including the frequent use of alcohol smoking, drugs, physical violence, vandalism, shoplifting and unjustified absences. In conclusion excessive gambling seems that goes along with other high risk behavior such as smoking, use of alcohol and drugs during adolescence, thus seems that gambling precedes other dangerous behavior and often starts during puberty.

\section{Definition and characteristics of problematic and pathological gamblers}

Gambling often is seen as adult behavior, but in the last years gambling is spread even among youngsters. Youngsters' gambling is identical to the adult's one. So gambling is an activity that implicates the risk elements during which participants can win or lose money or things of sentimental or monetary value. Specifically, gambling in youngsters can include sport bets, poker, dice games, bingo, card games, slot machines, ability games (basketball, bowling, swimming etc.) horse and dog races, internet gambling, scratch and win, national state lottery etc. Gambling in youngsters, causes also disorders in the main fields of life (psychological, physical, social and educational development) and are consider to be as progressive dependence characterized by:

- The increase of preoccupation about gambling

- The need to bet more and more money and even more regularly

- Worrying or getting nervous if are tried to be stopped

- The increase in the amount lost (the increase of the amount lost in order to substitute the amount lost previously)

- The lost of control manifested by the permanence of gambling under serious negative consequences

Often we are faced with youngsters asking questions such as gambling illegal? Does gambling make you dependant? How does it differ from other forms of dependence?

First of all, the age in which gambling is allowed varies from a place to another and from a country to another and just as the minimum age varies on different types of games (gambling in casinos versus television lotteries).

A general and accepted rule is that gambling is legal for a 18 year old or older. However because of the large variety of gambling, individuals may ask for the inner regulation of these gambling points. 
Gambling versus other addictions. Gambling is similar to other addictions such as drug and alcohol abuse, in different ways, but is similar in other directions. Problematic gamblers just a drug and alcohol abusers have an incapability to stop or to control their behavior. Problematic gamblers and addicted people are preoccupied with their addiction and need to get engaged in continuous activities to achieve a higher degree of satisfaction. A significant difference between gambling problems an narcotic substance abuse is that gambling is often a hidden addiction, not easily visible or detectable. Another significant difference is the heavy impact that gambling has on the gambler's life. If an individual once decides to stop drinking alcohol, he can be on the way of recovery. Whereas if an individual decides to stop gambling even if he succeeds in doing so ,he will always be under the pressure of giving explanations for what is usually a large amount of money lost. This fact creates an even stronger temptation for him losing-trying, in an attempt to win money to reduce the debt. Also all addictions may result in negative emotional and social consequences, but problematic gamblers don't experience physical damage (such as: overdose, liver damage, underestimating judgments etc.) as a direct consequence of gambling. However problematic gamblers experience serious social consequences related to cheating and the lack of trust of their friends and close people.

Why do youngsters hide behind gambling? There are four types of gamblers: social gamblers, those in danger (play, but gambling doesn't affect any of their fields of life); problematic gamblers (gambling affects in some of their fields of life) and pathological gamblers (their thoughts and actions are only about gambling and it strongly affects all their fields of life). Individuals don't play only for pleasure, but a strong impulse is also the possibility to win money, living the excitement that individuals experience through gambling, getting away from home, school or other places problems and to experience relief from feelings such as loneliness, depression or other unpleasant feelings. The tendency of a youngster to gamble, usually grows as a consequence of his need for immediate pleasure, the hope to become rich fast. They see gambling as a mean to improve their social state or as a feeling of getting away from home, school or other places, thing that has brought the increase of gambling through internet (Vitaro, Arseneault, \& Tremblay, 1999; Ladouceur, Boudreault, Jacques, \& Vitaro, 1999).

Expansion. Canadian studies of students of $7^{\text {th }}$ to $11^{\text {th }}$ grade (Ladouceur, Boudreaul, Jacques, \& Vitaro, 1999) and in $4^{\text {th }}$ to $6^{\text {th }}$ grade (Ladouceur, Dube, \& Bujold, 1994) have seen that approximately $87 \%$ of them have played at least once in their lives. In another study $47 \%$ of $7^{\text {th }}$ grade students in Massachusetts, had bought lottery tickets and around $3 \%$ of them had bought lottery tickets from 6 to 19 times during the months (Shaffer, 1994). In an analysis of United States and in a Canadian study on youngsters gambling, Shaffer and Hall (1996) found out that teenagers presented behaviors of problematic and pathological gambling in a percentage that varied from $4.4 \%$ to $7.4 \%$. Approximately $5.4 \%$ of adults may be considered problematic gamblers, as a consequence of the range of problems or connection they have had with gambling in their teens, this means that problematic and pathological gambling may have a wider expansion in teenagers than in adults.

In a study carried out with British teenagers aging from 13 to 14 years old, it was seen that the main age of starting gambling as a social entertainment was 8.3 years old for boys and 8.9 for girls (Ide-Smith \& Lea, 1988). Other studies show that pathological gamblers start gambling at an average age of 10.9 years old and those non pathological at an age of 11.5 years old (Gupta, 1998a; 1998b). From a retrospective study was seen that adult gamblers remembered to have started gambling between the ages of 10 to 19 years old.

From an independent study carried out in Albanian high schools and universities (1000 students and pupils in total) ${ }^{1}$ it resulted that $39 \%$ of teenagers interviewed admit they have started to gamble before the age of $11 ; 51 \%$ between the age of 11 and 15 ; and $10 \%$ after the age of $15.32 \%$ admit they have played at least once a week. Between $23 \%$ and $40 \%$ of teenagers in this study admit they have wanted to stop gambling, but they couldn't. These figures lead us to the conclusion that a considerable number of teenagers aging from 14 to 19 have serious problems with gambling.

\section{Risk factors}

Youngsters with a high degree of particular personality traits such as impulsiveness, extraversion and a feeling of demand, may have a high probability to develop problematic gambling behavior (Dickson, Derevensky, \& Gupta, 2002). A study carried out by Dickson in 2002 suggested that males are more inclined than females to become problematic gamblers, although females are more inclined to show problems with gambling earlier. Youngsters with a low level of self esteem, compared with other teenagers are more at risk of gambling problems. Youngsters, like problematic gamblers, usually have at least one parent addicted to gambling, alcohol or drugs, or have parents involved in illegal activities. Youngster's parents who are problematic gamblers often have lack of information regarding problems of teenagers

${ }^{1}$ This study was focused on 4 high schools and 2 universities in Tirana and Durrës (2010) 
relating to gambling. Just like any other addiction gambling problems in youngsters are accompanied with a high degree of depression, ideas and attempts of suicide (Dickson et al., 2002). However, every case of problematic gambling is unique and has particular causes and consequences.

\section{Signs and symptoms of problematic gambling}

Young gamblers, are included in many different kinds of gambling and often show different signs and symptoms, among which is possible to understand if they have problems with gambling. Below are listed some of these symptoms of gambling in youngsters.

Symptoms related with behavioral changes at school and at home.

- Unjustified absences at school

- Low grades

- Demand for money or borrowing from peers

- Withdraw from family

- Behavior change (daydreaming, worries, mood swings, lack of participation, they feel tired at school, changed and disturbed sleep patterns, food disorders)

- Lying, deceiving, or stealing at school

- Spending unusual amount of time reading newspapers, magazines and/or materials with periodical information on sport

- Selling personal belongings

- Accusations and unexplained justifications in relation with excessive expenses.

- Owing unexplainable large amount of money or other wealth objects (cars, clothes, jewellery, etc)

\section{Specific gambling behaviors}

- Different types of gambling on internet.

- Increase of interest for discussions on gambling

- Use of gambling jargon in their daily conversations in an unaware manner (betting, spread of place where you gamble, loser or favorite, exaggerated use of the word 'bet'

- Boasting for their winnings

\section{Evaluating and treating gambling problems}

There are many ways to evaluate the presence or the degree of gambling problems in youngsters ${ }^{2}$. The larger part of the surveys are self-reporting measures and have 20 or less questions, allowing in this way individuals not to spend a lot of time and to make an easy examination to complete and understand it. Many evaluating methods are modified and adopted to specific problems and behavior of youngsters and teenagers as gamblers. With these methods, we should be careful, because their purpose is to serve as a mean of analysis and not as a mean of diagnostic. Researchers are continuing to create means and specific methods for teenagers and youngsters that go towards gambling. Teachers may consult mental and social health and specialists (school sociologist, social workers, and counselors) in relation to problems, worries or consequences that this analysis can lead to with youngsters themselves, with peers, teachers or society. The more increases the awareness of gambling problems in youngsters the more increases the knowledge of effective practices of treatment. Just like the behavior in other kinds of addictions, even in problems of gambling addiction in youngsters, seems that the Cognitive-Behavioral approach may be successful. A key aspect of treatment is the help it can be given to youngsters to identify their wrong and right thoughts, also the help it can be given to them to develop such skills that monitor their thought about gambling and to develop other substitute behavior. An important difference between gambling addiction and different narcotic substances addiction is that gamblers cannot escape easily from their debts. The collaboration for solving the problems about the reduction of the debts can help the gamblers to feel less depressed. Self-help groups can be a very valuable part of the process of gamblers recovery. In the world these groups

2Look at "Instruments for examination and classification" in the end of this article 
have given very good results, but generally are implemented in adults and there are no documents of having such groups with teenagers. Another group of help for the close family members of a gambler is the group "Gam - Anon" (anonymousgambler) in which family members gather regularly to share their experiences, the force and the hope to face the gambling problems that one of their family members have.

\section{What can schools do in order to help smoothing or decreasing the gambling problems in youngsters and teenagers}

School psychologists, social workers and other school employees specialized in mental health issues have a unique chance to identify the students with gambling problems. When the symptoms of gambling problems are still invisible, professional people in the school must investigate in the routine way they do when investigate the use of drugs and alcohol. Schools can facilitate prevention, identification and treatment of gambling problems in youngsters. School staff can make the connection of parents and students with the sources within the community. It is important to ask a youngster if he has ever gambled before and if he is experiencing some of the indicators that are used to identify the problems connected with gambling. If a youngster admits he has gambling problems schools (psychologists) must be able to offer professional services inside the group of pupils in particular, but also in school in general.

Mental health professional inside schools, also should closely monitor students, whose parents have or have had known problems with gambling. The children of problematic gamblers have a high predisposition to develop themselves gambling problems (Gupta \& Derevensky, 1998). They also may experience high levels of stress inside their families, if one of the parents is experiencing gambling problems.

The models of effective prevention we should include (Dickson, Derevensky \& Gupta, 2002):

- Activities which increase the level of knowledge about gambling problems in youngsters

- Experiences that help in modifying and changing the idea that gambling is always a non harmful behavior.

- Discussions that help in changing the wrong knowledge relating to the role of abilities and luck as well as the illusion of self control during the game

- Demonstrations and written exercises in a notebook ore board, to understand the statistic probability and superstitions

- The creation of possibilities for students to learn successful abilities which may prevent the developing of gambling problems.

The last decade has witnessed an increased in the number of prevention programs worldwide, which aim at the reduction of youngsters and teenagers inclusion in gambling. The programs which are actually being implemented in many countries of the world, are based in the increase of understandability of probability laws and in the demystification of the myth that in gambling is more important the ability and the luck. The implementation doesn't require any entirely new program during schooldays. Often, preventing gambling activities can easily be added to school programs with preventing effects like the topics about drug and alcohol prevention, violence in the family prevention, or other topics that are discussed in the program of social education. The classification of life skills can also be a suitable and effective way to treat gambling problems. Also the topics on probability and the role of ability and luck can be treated in the Mathematics curricula. In this way for instance the possibility to be a winner in gambling depends a lot on the probability of happening what the players wants, so the probability to win a roulette game is 1 in 38 (there are 38 slots) in dices the probability to win is 1 in 36 (there are 2 dices with 6 numbers: 6x6 $=36$ combinations) in blackjack is 1 in 21 and so on. There are data that responsible for gambling problems is allele D2A1 (Comings, 1998) which is connected with a range of addictive behaviors and impulsive disorders (Blum, 1996), where D2 is the genetic receptor and A1 is the level of dopamine. Theoretically the specific human genes are connected with biochemical reactions and reinforcing mechanisms in the brain, determining the impulsive behavior and the addiction. Gambling is perceived in the brain by the cells and the signal molecules and through neurons that translate it in pleasure and reward for certain behavior. Scientific research, during the study of people who gamble, have shown the connection between dopamine and pathological gambling (Comings, 1998; Perez de Castro, 1997). Moreno and DeCaria, during their study on a sample of gamblers, found out the connection between serotonin and pathological and problematic gambling. A special attention is given to the limbic system in the intermediating acute mechanisms of reinforcement which are including in pathological gambling. Such results can easily intertwined in the existing Biology curricula and health education and especially in the curricula of psychology and sociology covering in this way a treatment of gambling in the levels of 9-years schools, high schools and universities. Only by presenting the topic of gambling for discussing the addiction can awareness be risen and can be encouraged the perception that gambling can be a harmful behavior. Schools can choose to implement any independent 
program for preventing or can include the awareness and prevention of gambling problems in existing prevention programs of drug and alcohol abuse.

Examples of program implementation may be found in many schools in the world, such as "Don't bet on it" - a program implemented for the children of ages 6 to 9 in South Australia schools; "Gambling Minimizing Health Risks" in Queensland for the children of $5^{\text {th }}$ and $6^{\text {th }}$ grade; "Facing the Odds" in Louisiana for children from the $5^{\text {th }}$ grade to the $8^{\text {th }}$ grade; "Wanna Bet" in Minnesota for children of $3^{\text {rd }}$ grade to $8^{\text {th }}$ grade; "Gambling: A Stacked Deck" in Alberta and in the Mathematics and Statistic curricula of Harvard/Massachusetts for high school students (Jeffrey L Derevensky \& Rina Gupta, 2011).

In the last 20 years International Center for Gambling Problems and High Risk Behavior in Youngsters, in McGill University, the best in Canada, has examined the risk and protective factors and based on them has created some programs for teachers but not only, which may be adopted for work in class. These strategies are created for different levels of students and some of them require less intrusion. These programs are suitable for the teachers who doesn't have knowledge on gambling issues and its problems, as well as for teachers that have limited time as a result of full curricula of the subject they cover. Many of these programs are being implemented momentarily in America; Canada; Europe; Australia; New Zealand; and Singapore (Jeffrey L Derevensky \& Rina Gupta, 2011).

Gambling is becoming more accepted than ever before and is being considered as a pastime (when the effects and the consequences are so negative for the individual's life and the whole society), not only for the adults, but also for youngsters and teenagers. With the large expansion that gambling is having, the increase of gambling problems is becoming more evident. As the leading actors, school professionals have a unique possibility to facilitate prevention, to identify and treat youngsters who have gambling problems and to know the impact that gambling has on the family.

\section{Examination and classification instruments}

- Assessmentof gambling addiction www.gambler-assessments.com/

- 20 questions for anonymous gamblers www.gamblersanonymous.org/20questions.html

- Examination of gambler www.gamblercaritas.org.hk/assessment_e4.htm

- Examination of gambling (Southern Oak)-Revised for Adolescents www.npgaw.org/media/pdfs/PDF3.pdf

\section{References}

Blum, K., J. G. Cull, E.R. Braverman, and D.E.Comings; (1996) Reward deficiency syndrome: Addictive, impulsive and compulsive disorders including alcoholism, attention-deficit disorder, drug abuse and food bingeing may have a common genetic basis American Scientist 84: 132-145

Carlson MJ, Moore TL (1998) Adolescent Gambling in Oregon: A Report to the Oregon Gambling Addiction Treatment Foundation. Salem, OR

Comings, D. E., (1998)The molecular genetics of pathological gambling; CNS Spectrums 3 (6): 20-37

Dickson, L. M., Derevensky, J.L., \& Gupta, R. (2002). The prevention of gambling problems in youth: A conceptual framework. Journal of Gambling Studies, 18, 97-159.

DeCaria, C.M., T. Begaz and E. Hollander, (1998) Serotonergic and noradrenergic function in pathological gambling,; CNS Spectrums $3(6): 38-47$

Gupta, R. \& Derevensky, J.L., (1998). Adolescent gambling behavior: A prevalence study and examination of the correlates associated with problem gambling. Journal of Gambling Studies, 14, 319-345.

Gupta, R., \& Derevensky, J.L. (1996). The relationship between gambling and videogame playing behavior in children and adolescents. Journal of Gambling Studies, 12, 375-394.

Gupta, R., \& Derevensky, J. L. (1998b). An empirical examination of Jacobs' General Theory of Addictions: Do adolescent gamblers fit the theory? Journal of Gambling Studies, 14, 17- 49.

Ide-Smith, S. G., \& Lea, S. E. (1988). Gambling in young adolescents. Journal of Gambling Behavior, 4(2), 110-118.

Jeffrey L Derevensky, and Rina Gupta (2011); School of Applied Child Psychology; International Centre for Youth Gambling Problems and High-Risk Behaviors, McGill University, Canada

Ladouceur, R., Boudreault, N., Jacques, C., \& Vitaro, F. (1999). Pathological gambling and related problems among adolescents. Journal of Child and Adolescent Substance Abuse, 8, 55-68.

Ladouceur, R., Dube, D., \& Bujold, A. (1994). Gambling among primary school students. Journal of Gambling Studies, 10, 363370. 
Moreno, I., J.Y.Saiz-ruiz, and J.J Lopez-Ibor, Serotonin and gambling dependence. (1991) Human Psychopharmacology 6:S9$\mathrm{S} 12$

Perez de Castro, I., A. Ibanez, P. Torres, J. Saiz-Ruiz, and J. Fernandez-Piqueras, (1997) Genetic association study between pathological gambling and a functional DNA polymorphism at the D4 receptor gene. Pharmacogenetics 7(5):345348Potenza. (Eds.), Pathological gambling: A clinical guide to treatment (1st ed., pp. 69-79).

Randy, S., \& Ken, C. W. (2004). Adolescents and young adults. In J. E. Grant, \& M. N. Potenza. (Eds.), Pathological gambling: A clinical guide to treatment (1st ed., pp. 69-79).

Shaffer, H. J., \& Hall, M. N. (1996). Estimating the prevalence of adolescent gambling disorders: A quantitative synthesis and guide toward standard gambling nomenclature. Journal of Gambling Studies, 12, 193-214.

Shaffer HJ (1994) Pathological gambling among adolescents: Massachusetts Gambling Screen (MAGS). Journal of Gambling Studies 10: 339-362

Vitaro, F., Arseneault, L. \& Tremblay, R. E. (1999). Impuslivity predicts problem gambling in low SES adolescent males. Addiction, 94, 565-575.

Volberg, R. A., and H.J. Steadman (1998) Refining prevalence estimates of pathological gambling. American Journal of Psychiatry 145(4): 502-505

Winters, K.C., R. Stinchfield, and J. Fulkerson (1993) Patterns and characteristics of adolescent gambling. Journal of Gambling Studies 9(4): 371 - 386

Wynne, H., Smith, G., \& Volberg, R. (1994). Gambling and problem gambling in Alberta. Edmonton, A. B., Canada: Alberta Lotteries and Gaming.

Wynne Resources: (1998) Adult Gambling and Problem Gambling in Alberta. Edmonton, A. B., Canada: National Academy Press Wynne Resources.

Wynne, H. J., Smith, G. J., \& Jacobs, D. F. (1996). Adolescent gambling and problem gambling in Alberta. Report prepared for the Alberta Alcohol and Drugs Abuse Commission. 
